\title{
Epidemiological and Physiological Approaches to Understanding the Etiology of Pediatric Obesity: Finding the Needle in the Haystack
}

\author{
JOHN J. REILLY, ANDREW R. NESS, AND ANDREA SHERRIFF
}

\begin{abstract}
Division of Developmental Medicine [J.J.R], University of Glasgow, Yorkhill Hospitals, Glasgow, Scotland, G3 8SJ, United Kingdom; Department of Community Based Medicine [A.R.N., A.S.] and Department of Oral and Dental Science (A.R.N.), University of Bristol,
\end{abstract} Bristol, England, BS8 1TQ, United Kingdom

\begin{abstract}
Recent increases in the prevalence of childhood obesity have created an urgent need for preventive strategies, but such strategies in turn depend on an improved understanding of the etiology of pediatric obesity. There is a dearth of evidence of the cause of pediatric obesity at present, with much of the literature of limited quality, inconclusive, and contradictory. The present review highlights the paradox of energy imbalance-its apparent simplicity but actual complexity-and the difficulties in etiologic research that arise from this complexity. The review identifies a number of emerging problems for etiologic studies. The review also makes a number of proposals that might improve future etiologic studies and provides a framework for integrating the diverse body of evidence of etiology that will become available in future. Gathering improved evidence of etiology, and then integrating and interpreting it, will take many years. In the meantime, an emphasis on developing more effective preventive interventions is necessary. (Pediatr Res 61: 646-652, 2007)
\end{abstract}

$\mathrm{O}^{\mathrm{h}}$ besity continues to increase rapidly across much of the world (1-5). In England, obesity prevalence defined as body mass index $(\mathrm{BMI}) \geq 95$ th percentile relative to UK 1990 reference data (4) in 11-15 y olds was $25 \%$ in 2004 (5) compared with $17 \%$ in 1996 (6) and 5\% by definition in 1990 (4). In Europe, the rate of increase in childhood obesity prevalence is itself increasing (3). The obesity epidemic is therefore recent, and this is one reason why its etiology is not well understood at present. Secular trends to a more central body fat distribution and increasing body fatness appear to have occurred across the distribution of children (7-13), so many more children have been affected by the epidemic than obesity prevalence data based on BMI might suggest.

The combination of high and increasing prevalence of obesity, limited evidence supportive of specific preventive interventions summarized in systematic reviews $(14,15)$, evidence of adverse effects of obesity from systematic review (16), and uncertainty about etiology, provides great cause for concern. In this review, we examine the origins of the etiologic uncertainty, suggest improvements in the design and analysis of etiologic studies, and propose a framework for integrating the diverse body of evidence of etiology.

Received January 2, 2007; accepted January 9, 2007.

Correspondence: John J. Reilly, Ph.D., University of Glasgow, Yorkhill Hospitals Division of Developmental Medicine, Glasgow, Scotland, G3 8SJ, UK; e-mail: jjr2y@clinmed.gla.ac.uk

DOI: $10.1203 / p d r .0 b 013 e 3180536667$
The specific aims of the present review are therefore to (1) highlight the paradoxical complexity of the etiology of obesity; (2) identify emerging problems in etiologic research; (3) suggest ways in which energy balance studies (which attempt to attribute etiology to energy intake and/or energy expenditure) and epidemiologic studies (which try to identify exposure variables for obesity) might be more productive in future; (4) suggest approaches to integrating the diverse body of evidence of etiology now available.

\section{ETIOLOGY OF OBESITY: THE ENERGY BALANCE PARADOX}

Because obesity is an energy balance disorder, caused only by a chronic excess of energy intake over energy requirement, its origins seem very simple and obvious, particularly if we consider energy balance as a simple static model where any change in intake or expenditure produces a net change in energy balance. In these terms, obesity is the result of only three possibilities: increased energy intake, decreased energy expenditure, or both of these.

In reality, the origins of energy imbalance are more complex than our simple static model would suggest, for a variety of reasons. First, measurement issues make it difficult to attribute obesity to energy intake or expenditure. These are two large terms in our model that are measured with limited accuracy and precision (energy intake is measured particularly poorly), and the energy imbalance that might lead to obesity can be very small and difficult to discern among the "noise" of energy turnover $(17,18)$, akin to "looking for a needle in a haystack." Second, the static model is overly simplistic because the intake and expenditure components of the model are not independent. We regulate our energy balance, to some extent at least, by coupling intake and expenditure and so a perturbation in one term in our model, such as a decrease in energy intake, can produce compensatory changes in the other terms, by reducing energy expenditure at rest or energy expended on physical activity (19). However, an emerging body of evidence (20) predicts that coupling of intake and expen-

\footnotetext{
Abbreviations: ALL, acute lymphoblastic leukemia; ALSPAC, Avon Longitudinal Study of Parents and Children; DEXA, dual energy x-ray absorptiometry; DLW, doubly labeled water method; NEAT, nonexercise activity thermogenesis; REE, resting energy expenditure; TEE, total energy expenditure; $\mathbf{Z}$ score, SD score
} 
diture may become less effective at habitually low levels of energy expenditure. Third, a wide variety of different forms of evidence are available on the etiology of obesity (discussed below); these can produce evidence that is difficult to integrate. Fourth, although energy imbalance causes obesity at the level of the individual, subtle societal influences on energy intake and expenditure are presumably the underlying or true "causes" of obesity (21), yet these are extremely difficult to measure or even identify. Finally, an emerging body of epidemiologic evidence, discussed below, suggests that etiology of obesity may differ significantly between different groups of children within populations, and so if we are to understand etiology, we may need-extending our analogy—to find many needles in many different haystacks. For all these reasons, the etiology of obesity is in fact much more complex than it seems and less well understood than a lay or media view of it might imagine. An improved understanding of etiology is central to more successful prevention of obesity, in particular, the identification of modifiable exposure variables or risk factors is a high priority (22).

\section{ENERGY BALANCE APPROACHES TO ETIOLOGY}

In disease states of childhood that are characterized by either underweight (e.g. cystic fibrosis) or overweight and obesity (e.g. acute lymphoblastic leukemia, ALL) the etiologies of under- and overweight have been explained using energy balance methods that have used the simple static energy balance model (23). These etiologic studies may have "succeeded" in part because they involve extreme populations experiencing substantial rates of energy imbalance and relatively rapid weight gain, for example, deficits in habitual total energy expenditure (TEE) in preobese children with ALL of $>1 \mathrm{MJ} / \mathrm{d}$ and periodic increases in habitual energy intake of $>1.5 \mathrm{MJ} / \mathrm{d}$ (24-26). Although the degree or rate of energy imbalance being experienced by the general pediatric population may be smaller than in this clinical example and a process of "creeping weight gain" may be more common (18), this remains to be tested empirically in contemporary children. One study of a group of healthy children and adolescents at high risk of obesity in the United States found exceptionally high rates of excess weight gain (27) and suggested that the degree or rate of habitual energy imbalance may be sufficiently high to be amenable to study, even with our limited energy balance methods (28). Another more recent study from the United States also suggested that contemporary children exhibit a greater degree of positive energy balance than might have been expected (29). Methodologic lessons learned from clinical studies of energy imbalance may be helpful in providing an improved understanding of the etiology of obesity in the pediatric population, and these are summarized in Table 1.

The clinical studies may also have succeeded because their design was based on a good understanding of the natural history of obesity, e.g. in ALL, the natural history is well understood (30), to identify children in the preobese state. The clinical studies have been successful in testing hypotheses that have been generated by the natural history studies (24-26). Studies of TEE and its relationship to subsequent weight or fat
Table 1. Lessons from etiologic studies of energy imbalance in chronic disease states of childhood

\section{Measurement methods}

Should be comprehensive; measure all components of energy balance (intake, REE, TEE) in same participant at the same time

Measure TEE with DLW if possible

Measure body composition and use it to adjust measures of REE and TEE

Consider measurement of NEAT or its components, such as fidgeting or posture allocation

Study design:

Base design on natural history studies; study children during likely periods of energy imbalance

Use longitudinal study design and analysis where possible

Consider using each participant as his or her own control, e.g. studying the same children under different circumstances

Match controls closely for the main determinants of energy expenditure (body size and composition, sex, possibly season, school days/school holidays)

REE, resting energy expenditure; DLW, doubly labeled water method; NEAT, nonexercise activity thermogenesis.

gain in the general pediatric population have been scarce, usually inconclusive, and usually based on relatively small samples ( $n<100$ per sex) of children at relatively low risk of obesity rather than children who might reasonably be expected to be preobese (28).

Etiologic studies of REE and TEE in the general pediatric population might be more productive if they are focused on groups at higher risk of obesity and recruit larger samples. With the sustained availability of ${ }^{18} \mathrm{O}$-labeled water (for the DLW method of measuring TEE in free-living children) at relatively low cost, larger studies to test the role of TEE in subsequent obesity development will become possible, and we suggest that such studies focus on groups identified as being at particularly high risk of obesity such as children of low socioeconomic status, children of obese parents, or children from ethnic minority groups, as these are the most likely to be experiencing the high rates of energy imbalance necessary for investigation by our traditional energy balance methods. As an example, we calculate that an association between baseline TEE and subsequent excess weight or fat gain in prepubertal children could be identified in a longitudinal study as a correlation coefficient or standardized regression slope of 0.2 at the 5\% level with $80 \%$ power with a sample of around 190 boys and 190 girls. With an allowance for dropout, this would require a baseline sample of perhaps 450 children. At current costs of the ${ }^{18} \mathrm{O}$-labeled water (and mean weight $30 \mathrm{~kg}$ ) for the DLW method, isotope costs for such a study would not exceed $\$ 65,000$, which should not be prohibitive.

\section{EPIDEMIOLOGIC APPROACHES TO ETIOLOGY}

Wells (31) made the case for more epidemiologic approaches to the study of the etiology of obesity, arguing that the degree of energy imbalance involved is too small to be measurable with energy balance methods. Identifying exposure variables by epidemiologic approaches might therefore be more productive. In the longer term, epidemiologic approaches that identify important exposure variables may also be of greater practical value in obesity prevention because, in 
contrast to physiologic approaches based on energy balance, they provide answers in the form of behaviors that can be targeted in subsequent prevention strategies (31).

One major problem with epidemiologic approaches to etiology is that a systematic review published in 1999 (32) concluded that many of the epidemiologic studies in the literature were very limited; inadequately designed to identify causality (cross-sectional studies dominated the literature up to the late 1990s and are still common); usually underpowered; often used simple (univariable) approaches to analysis; and were usually dependent on very crude measures of exposure and/or outcome variables. Parsons et al. (32) recommended that future epidemiologic attempts to understand the etiology of childhood obesity should be more rigorous: use a longitudinal design, be adequately powered, and use more precise measures of exposure and outcome with more sophisticated (multivariable) approaches to statistical analysis. The epidemiologic literature on the etiology of childhood obesity has improved since the publication of the Parsons et al. review (32), but uncertainty remains, even over the better established exposure variables: formula feeding during infancy; rapid growth in early life; sedentary behavior, particularly screen time/media use; low physical activity; and sugar-sweetened drink consumption $(33,34)$. Two issues arise from this uncertainty: first, how to conduct and analyze epidemiologic studies in future to increase confidence in our conclusions and, second, how to integrate and appraise the body of epidemiologic and other evidence to identify factors involved in the causation of obesity with sufficient confidence.

\section{MEASUREMENT OF EXPOSURE AND OUTCOME VARIABLES}

Previous reviews have noted the importance of measurement accuracy and precision in identifying and quantifying associations between exposure variables and obesity-related outcomes $(35,36)$. Inadequate measures may obscure true associations or reduce the apparent magnitude of associations. Here we note the recent availability of greatly improved measures of some risk factors, e.g. the advent of objective measurement of physical activity and sedentary behavior using accelerometry (35), suitable even for large-scale epidemiologic studies such as the Avon Longitudinal Study of Parents and Children (ALSPAC) $(37,38)$. Epidemiologic etiologic studies have not considered measures of energy expenditure as exposure variables in the past, but we can now include measurement of REE (measured by portable indirect calorimeters), TEE (measured by DLW method), and physical activity energy expenditure (PAEE), calculated as the difference between TEE and REE with a standard correction for the thermic effect of feeding in pediatric epidemiologic studies. Better measures of physical activity and sedentary behavior, based on accelerometry (39), should be considered for measurement of exposure in future. We note that PAEE in children is also known as NEAT (40) and that variation in some of the low-level movements encompassed within NEAT, such as fidgeting, might be important in explaining differential susceptibility to obesity in children, although this has not been investigated in the absence of measurement techniques for such variables in children. If methodologic developments permit such subtle measures in future, these should also be considered as exposure variables in future epidemiologic studies Furthermore, recent technologic developments may improve the practical utility, accuracy, and precision of estimation of TEE and PAEE even further using accelerometry in combination with other methods $(41,42)$.

Traditionally, measurement of outcome variables (obesity/ weight status) has been more accurate and precise than measurement of many exposure variables in epidemiologic studies (35). Weight and height are relatively easy to measure in large samples, although they are not perfect indices of body composition for etiologic purposes. For many important potential risk factors, particularly for dietary risk factors, for example (43), measurement accuracy and precision are poor and participant burden is high, so associations between putative risk factors and outcome can be tested with greater confidence for some risk factors than others. This may be an argument both for the development of improved measurement methods for risk factors that are measured poorly and for greater focus on obtaining good measures of those risk factors that can be measured well using existing methods, such as the use of objective measurement of physical activity by accelerometry rather than subjective assessment using questionnaires (35). One difficulty with this approach might be that we put greater research effort in future into including risk factors in our etiologic studies that can now be measured well, i.e. with high accuracy and precision and low participant burden, such as physical activity, but neglect putative exposure variables that are not measured well, but that are likely to be very important in etiology (such as various aspects of dietary intake). Methodologic research aimed at providing accurate, precise, and practical measures of all the potentially important exposure variables is therefore a high priority if our understanding of the etiology of pediatric obesity is to improve in future.

Outcome measurement in most epidemiologic studies of etiology has been based on a high BMI SD score or $Z$ score. Systematic reviews have shown that high BMI $Z$ score is a good, perhaps surprisingly good, measure of high fat mass (1), but at lower points in the BMI distribution a very wide range of fat masses exist at the same BMI SD score ( $Z$ score) $(1,44,45)$. The use of mean BMI $Z$ score is a poor measure of overweight and obesity in a sample. For example, the mean BMI $Z$ score has proved problematic in studies that have examined the role of socioeconomic status in the development of obesity (46) and has obscured the possible protective role of breast-feeding in obesity because breastfeeding probably protects against both underweight and overweight and so has a less marked effect on mean BMI than at the extremes of BMI (47).

So long as obesity (a high fat mass associated with increased risk of morbidity) is the outcome of interest, a high BMI $Z$ score will be an acceptable and readily obtained outcome in large epidemiologic studies. The use of "international" definitions of obesity in children and adolescents may reduce power by defining relatively small numbers of participating children as obese because they are overly conservative 
definitions with particularly low diagnostic sensitivity for a high body fat content (1). Another potential problem with the international definitions is that they provide definitions that are not equivalent between boys and girls (diagnostic sensitivity differs significantly between the sexes, in contrast to defining obesity relative to national reference data) (1).

There are now a number of more sophisticated epidemiologic measures of outcome available, based on measurement of body composition $(48,49)$. In longitudinal studies of the development of obesity in children, measurement of body composition has been more informative than BMI in some studies (50). It is also helpful to consider fat mass as a continuous outcome variable rather than as a categorical or dichotomized variable $(36,37)$, and ideally fat and fat free masses would be adjusted for height using an approach such as the fat-mass index, and estimated using more precise methods such as dual-energy x-ray absorptiometry (DEXA) (51-53). The high precision of DEXA makes it particularly well suited to measuring change in body composition in longitudinal studies, and it is very acceptable to children. However, validation studies against criterion multicomponent models have shown that DEXA does not estimate fat mass with high accuracy $(54,55)$, and at present, no field methods have high accuracy relative to criterion methods with the possible exception of total body water $(48,49)$, which is not a straightforward method for field use.

\section{EFFECT MODIFICATION WITHIN POPULATIONS}

One concern for etiologic studies of obesity in childhood is the emerging body of evidence from the United States that the etiology of obesity may differ markedly between groups within a population. Groups might differ not just by the level of exposure to variables that cause obesity, but there may be different causal variables operating in different groups defined by socioeconomic status $(56,57)$, race/ethnicity $(56,58)$, or initial weight status (50). Establishing whether such differences in etiology exist in societies outside the United States is therefore important. If marked differences in etiology exist between groups within a population, then this implies that many etiologic studies will be necessary in future or that future etiologic studies must be even larger to represent the various groups of interest within each population.

\section{STRATEGIES TO REDUCE THE IMPACT OF CONFOUNDING}

There is increasing awareness of the importance of both residual and unmeasured confounding, and specifically of their likely impact on etiologic studies of obesity $(35,36)$. It is notoriously difficult to disentangle the effects of potential exposure variables on obesity when many of these associations are confounded by social factors. However, the impact of confounding can be reduced by attention to the strategies listed in Table 2.

\section{BUILDING THE STATISTICAL MODEL}

Formal stepwise methods based purely on statistical "rules" should not be used when developing an explanatory model for
Table 2. Strategies to reduce the effects of confounding in epidemiologic studies of the etiology of obesity

Include as many factors contributing to social patterning in the population as possible, e.g. maternal education, housing, social class, measures of deprivation, household income

Test for unattenuated dose-response effects likely to indicate an underlying biological process

Analyze proxy measures for the exposure along with the exposure of interest; similar associations imply a common rather than a specific and causal pathway*

Investigate the same associations in different geographic locations (ecologic studies), being aware of possible effect modification between populations

Test for the same associations in populations that show different confounding structures; if the association is still significant, this strengthens the likelihood that the association is causal

Check that associations are specific for the outcome of interest: if the exposure protects against a range of outcomes, it is more likely to be due to confounding by a cluster of lifestyle variables

Consider newer instrumental variable approaches such as mendelian randomization (59)

* When we recently tested for a previously reported association between maternal smoking and obesity, we also tested for, and found, similarly strong associations with paternal smoking (53), indicating that the associations may be more likely to reflect social factors rather than an underlying biological pathway from smoking to offspring obesity in this case.

the outcome (60). In broad terms, simple automated variable selection procedures artificially inflate the proportion of variation explained by the models that are selected and overestimate the regression coefficients. This results in poor predictive ability and means that the final models are not easily reproduced when minor changes to the data are made (e.g. slightly modified definitions of exposure variables such as breastfeeding). More specifically, to understand the etiology of obesity, we need an underlying conceptual framework upon which to build our statistical models, and this is likely to include variables that are not statistically significantly associated with the outcome but that have been identified as being important by previous studies and likely to lie on the causal pathway to obesity. Second, the process of model building should be sequential, such that factors should be offered to the model either singly or in predefined groups so that any attenuation (or amplification) of the association can be explained. A sequential approach to model building also helps reduce the likelihood of overcontrolling (36) because at each stage, the conceptual framework upon which the model is being built should be considered. Finally, any interactions to be tested should be based on a priori hypotheses. Automated stepwise procedures will test all possible interactions within a model, increasing the probability of chance findings.

\section{LONGITUDINAL ANALYTICAL METHODS}

Longitudinal studies provide detailed information on changes within participants over time. There appear to be a number of pathways (etiologies) to obesity by childhood and adolescence $(56-58,61)$. Cross-sectional studies cannot address the important questions that arise in longitudinal studies. Unfortunately, longitudinal studies remain scarce, and, as pointed out by Must and Tybor (36), longitudinal studies are often analyzed using univariate models based on some sum- 
mary measure (such as the mean) of the outcome measure over time. More complex and dynamic models are necessary to characterize complex developmental changes and to identify the determinants and covariates of change. Recent developments in the field of finite mixture modeling (62) allow for the identification of different developmental processes in distinct but unobserved subgroups within a sample. Finite growth mixture modeling extends the methods of random coefficients models to incorporate categorical latent trajectory variables representing latent classes, subgroups within the sample that are inferred from the data (62). The mixture modeling method is a modeling framework for mapping substantive hypotheses of development onto appropriate statistical models. This promising approach is now being used occasionally in the study of the etiology of pediatric obesity and its comorbidities $(63,64)$. It is a promising approach because it is likely that individual trajectories of weight status (e.g. change in fat mass or BMI $Z$ score) or probability of obesity (as a binary outcome) are heterogeneous but belong to a finite number of unobserved populations that have different means and associations within each subgroup. Additional strengths of this approach include the efficient handling and description of missing data and the ability to deal with intraindividual variation (between repeated measures) and the analysis of confounders, covariates, and possible exposure variables (62-64).

\section{INTEGRATING THE ETIOLOGICAL EVIDENCE}

A variety of alternative approaches are available for investigation of the etiology of pediatric obesity. A full description of these would be beyond the scope of the current review, but in brief these are, in addition to the energy balance and epidemiologic studies discussed above, as follows: systematic review and/or meta-analysis (32); intervention studies, particularly randomized, controlled trials $(65,66)$; mechanistic studies (e.g. use of animal models to elucidate underlying mechanisms, genetic studies). These approaches have been extremely useful in understanding etiology to date, and complement the epidemiologic and energy balance approaches to etiology, but all the approaches have important limitations.

The epidemiologic literature on the possible role for breastfeeding in protecting against later obesity is a good example of a large body of apparently contradictory evidence. The breastfeeding literature contains many recent studies that support the hypothesis that breast-feeding protects against later obesity, many that appear to reject the hypothesis, and a number of apparently inconclusive studies. The confusion and uncertainty over the role of breast-feeding in the avoidance of obesity have been diminished by recent meta-analyses (6769), although meta-analysis has pitfalls that should be borne in mind, and it is not likely to be a panacea to the problem of understanding the etiology of obesity (70). Systematic review/ critical appraisal has also recently proved to be extremely valuable in our understanding that rapid growth in early life is an etiologic factor in the development of obesity (71).

Weaknesses inherent in the epidemiologic approach to etiology, notably problems of confounding, may always limit our confidence in epidemiologically derived associations between risk factors and obesity-related outcomes (35). Single studies should be viewed with caution, and conclusions as to the major risk factors for the development of obesity should be based on a relatively large body of high-quality and consistent evidence. Associations that have biologic plausibility based on mechanistic studies are clearly more likely to be causally involved in the development of obesity. The possible role of sleep deficit in contributing to childhood obesity, identified from a recent longitudinal epidemiologic study (38), has been supported by a range of mechanistic and energy balance studies, including animal models $(72,73)$. An etiologic role for sleep deficit in childhood obesity development now seems much more biologically plausible.

Because some inherent weaknesses will remain even in large, well-designed epidemiologic studies, notably the problems of reverse causality and unmeasured and residual confounding $(35,36)$, alternative study designs will be necessary to provide greater certainty about cause. The highest level of evidence is from randomized, controlled trials. However, there are also problems in using the evidence base from such trials of interventions aimed at preventing childhood obesity. First, most of the older intervention trials have been described in numerous systematic reviews/critical appraisal exercises as being of poor methodologic quality $(14,15)$. Second, many of the higher quality and more recent trials of preventive interventions have failed to alter the behavior(s) in question significantly (74-76), and so cannot be used as tests of the hypothesis that altering physical activity and/or diet can modify the subsequent risk of obesity (34). In future, the evidence from randomized, controlled trials will only be informative if there is a massive expansion of and emphasis on funding of intervention research and if interventions that are more successful in changing behavior can be developed (77). A further difficulty is that some factors that may be involved in the causation of pediatric obesity are less amenable to modification and testing in randomized trials. As an example, random allocation to infant breast-feeding versus formula feeding is problematic, but even this is possible in some circumstances (78). For some exposure variables, evidence from randomized trials will be necessary to resolve doubts and controversy over their role in the causation of obesity.

\section{FROM ETIOLOGY TO PREVENTION OF PEDIATRIC OBESITY}

The present review has noted weaknesses in all the various approaches to identifying the causal pathways that lead to pediatric obesity. Must and Tybor (36) recently called for a "second generation" of improved longitudinal epidemiologic studies to improve the evidence base on etiology of obesity, and we support this view. While we wait for improvements in the evidence base-more and better intervention trials; more, better, and larger longitudinal observational studies; more mechanistic studies that establish biologic plausibility; studies that test for etiologic differences between groups within populations - the pediatric obesity epidemic continues apace (5). Interventions are required urgently and must therefore proceed on the best evidence available at present (77). Whitaker (33) 
has proposed a number of criteria or "decision rules" by which candidate risk factors/behaviors are selected as targets for obesity prevention, and this type of approach should be helpful in guiding the development of preventive interventions while we await improvements in the etiologic evidence from future studies.

\section{REFERENCES}

1. Reilly JJ 2006 Diagnostic accuracy of the BMI for age in paediatrics. Int J Obes (Lond) 30:595-597

2. Lobstein T, Baur L, Uauy R 2004 Obesity in children and young people: a crisis in public health. Obes Rev 5:4-85

3. Jackson-Leach R, Lobstein T 2006 Estimated burden of paediatric obesity and co-morbidities in Europe I. Part 1. The increase in the prevalence of childhood obesity is itself increasing. Int J Pediatr Obes 1:26-32

4. Cole TJ, Freeman JV, Preece MA 1995 Body mass index reference curves for the UK, 1990. Arch Dis Child 73:25-29

5. Reilly JJ 2006 Tackling the obesity epidemic: new approaches. Arch Dis Child 91:724-726

6. Reilly JJ, Dorosty A 1999 Epidemic of obesity in UK children. Lancet 354:18741875

7. McCarthy HD, Jarrett KV, Emmett PM, Rogers I 2005 Trends in waist circumference in young British children: a comparative study. Int J Obes (Lond) 29:157-162

8. Ruxton CH, Reilly JJ, Kirk TR 1999 Body composition of healthy 7-8 year old children and a comparison with the 'reference child'. Int J Obes Relat Metab Disord 23:1276-1281

9. Wells JC, Coward WA, Cole TJ 2002 The contribution of fat and fat-free tissue to body mass index in contemporary children and the reference child. Int J Obes Relat Metab Disord 26:1323-1328

10. Watkins DC, Murray LJ, McCarron P, Boreham CA, Cran GW, Young IS, McGartland C, Robson PJ, Savage JM 2005 Ten-year trends for fatness in Northern Irish adolescents: the Young Hearts Projects-repeat cross-sectional study. Int J Obes (Lond) 29:579-585

11. Thompson AM, Baxter-Jones AD, Mirwald RL 2002 Secular trends in the development of fatness in childhood and adolescence. Am J Hum Biol 14:669-679

12. Flegal KM 1993 Defining obesity in children and adolescents: epidemiologic approaches. Crit Rev Food Sci Nutr 33:307-312

13. Lohman TG 1993 The prevalence of obesity in children in the United States. In: Lohman TG, (ed) Advances in Body Composition Assessment. Human Kinetics Publishers, Champaign, IL, pp 307-312

14. Summerbell CD, Kelly S, Waters E, Edmunds L 2005 Interventions for preventing obesity in children. Cochrane Database Syst Rev 20;3:CD001871

15. Managing obesity in children and young people, a national clinical guideline: Scottish Intercollegiate Guidelines Network (SIGN) guideline no 69. Available at: www.sign.ac.uk. Accessed November 15, 2006

16. Reilly JJ, Kelnar CJ, Alexander DW, Hacking B, Stewart L, McDowell Z, Methven E 2003 Health consequences of obesity: systematic review and critical appraisal. Arch Dis Child 88:748-752

17. Goran MI 2001 Metabolic precursors and effects of obesity in children-a decade of progress, 1990-1999. Am J Clin Nutr 73:158-171

18. Hill JO, Wyatt HR, Reed GW, Peters JC 2003 Obesity and the environment: where do we go from here? Science 299:853-855

19. Leibel RL, Rosenbaum M, Hirsch J 1995 Changes in energy expenditure resulting from altered body weight. N Engl J Med 332:621-628

20. Stubbs RJ, Hughes DA, Johnstone AM, Horgan GW, King N, Blundell JE 2004 A decrease in physical activity affects appetite, energy, and nutrient balance in lean men feeding ad libitum. Am J Clin Nutr 79:62-69

21. Kumanyika SK 2001 Mini-symposium on obesity: overview and some strategic considerations Annu Rev Public Health 22:293-308

22. Dietz WH 2001 Breast-feeding may help prevent childhood overweight. JAMA 285:2506-2507

23. Reilly JJ 2002 Understanding chronic malnutrition in childhood and old age: role of energy balance research. Proc Nutr Soc 61:321-327

24. Reilly JJ, Brougham M, Montgomery C, Richardson F, Gibson BE 2001 Effect of glucocorticoid therapy on energy intake in children treated for acute lymphoblastic leukemia. J Clin Endocrinol Metab 86:3742-3745

25. Reilly JJ, Ventham JC, Ralston JM, Donaldson M, Gibson BE 1998 Reduced energy expenditure in pre-obese children treated for acute lymphoblastic leukemia. Pediatr Res 44:557-562

26. Warner JT, Bell W, Webb DK, Gregory JW 1998 Daily energy expenditure and physical activity in survivors of childhood malignancy. Pediatr Res 43:607-613

27. Butte NF, Ellis KJ 2003 Comment on "Obesity and the environment: where do we go from here?" Science 301:598

28. Reilly JJ 2005 Prevalence and causes of childhood obesity. CAB reviews: perspectives in Agriculture, Veterinary Science, Nutrition and Natural Resources. 1:13

29. Wang YC, Gortmaker SL, Sobol AM, Kuntz KM 2006 Estimating the energy gap amongst US children: a counterfactual approach. Pediatrics 118:e1721-e1733

30. Ventham JC, Reilly JJ 1999 Childhood leukaemia: a model of pre-obesity. Proc Nutr Soc 58:277-281

31. Wells JC 1998 Is obesity really due to high energy intake or low energy expenditure? Int J Obes Relat Metab Disord 22:1139-1140
32. Parsons TJ, Power C, Logan S, Summerbell CD 1999 Childhood predictors of adult obesity: systematic review. Int J Obes Relat Metab Disord 23:S1-S107

33. Whitaker RC 2003 Obesity prevention in primary care: four behaviors to target. Arch Pediatr Adolesc Med 157:725-727

34. Reilly JJ 2005 Physical activity and obesity in childhood and adolescence. Lancet 366:268-269

35. Wareham NJ, Van Sluis EM, Ekelund U 2005 Physical activity and obesity prevention: a review of the current evidence. Proc Nutr Soc 64:229-247

36. Must A, Tybor DJ 2005 Physical activity and sedentary behavior: a review of longitudinal studies of weight and adiposity in youth. Int J Obes (Lond) 29:S84-S96

37. Ness AR, Leary SD, Rogers IS, Wells JC, Mattocks C, Reilly JJ, Davey-Smith G, Riddoch C 2007 Associations between objectively measured physical activity and lean and fat mass in a contemporary cohort of children. PLoS Med 4:e97

38. Reilly JJ, Armstrong J, Dorosty AR, Emmett PM, Ness A, Rogers I, Steer C, Sherriff A Avon Longitudinal Study of Parents and Children Study Team 2005 Early life risk factors for childhood obesity: cohort study. BMJ 330:1357

39. Reilly JJ, Coyle J, Kelly LA, Burke GB, Grant S, Paton JY 2003 An objective method for measurement of sedentary behavior in 3-4 year olds. Obes Res 11:11551158

40. Levine JA 2004 Non-exercise activity thermogenesis. Nutr Rev 62:s82-s97

41. Corder K, Brage S, Wareham NT, Ekelund U 2005 Comparison of physical activity energy expenditure from combined and separate heart rate and movement models in children. Med Sci Sports Exerc 37:1761-1767

42. Crouter SE, Clowers KG, Bassett DR 2006 A novel method for using accelerometer data to predict energy expenditure. J Appl Physiol 100:1324-1331

43. Livingstone MB, Rennie KL 2005 Bio-behavioural determinants of energy intake and childhood obesity. In: Cameron N, Norgan NG, Ellison GT (eds) Childhood Obesity: Contemporary Issues. CRC Press, New York, pp 101-118

44. Wells JC 2000 A Hattori chart analysis of BMI in infants and children. Int J Obes Relat Metab Disord 24:325-329

45. Pietrobelli A, Faith MS, Allison DB, Gallagher D, Chiumello G, Heymsfield SB 1998 Body mass index as a measure of adiposity among children and adolescents: a validation study. J Pediatr 132:204-210

46. Yarnell JW, McCrum EE, Skidmore P, Shields MD, McMahon J, Evans AE 2001 Prevalence and awareness of excess weight in 13-14 year olds in Northern Ireland using recent international guidelines. Acta Paediatr 90:1435-1439

47. Grummer-Strawn LM, Mei Z 2004 Does breast-feeding protect against pediatric overweight? Pediatrics 113:e81-e86

48. Wells JC, Fewtrell MS 2006 Measuring body composition. Arch Dis Child 91:612617

49. Reilly JJ 1998 Assessment of body composition in infants and children. Nutrition 14:821-825

50. Stevens J, Suchindran C, Ring K, Guggett CP, Jobe JB, Story M, Thompson J, Going SB, Caballero B 2004 Physical activity as a predictor of body composition in American Indian children. Obes Res 12:1974-1980

51. Wells JC, Cole TJ, ALSPAC study team 2002 Adjustment of fat-mass and fat-free mass for height in children aged 8 years. Int J Obes Relat Metab Disord 26:947-952

52. Rogers IS, Ness AR, Steer CD, Wells JC, Emmett PM, Reilly JR, Tobias J, Smith GD 2006 Associations of size at birth and dual-energy X-ray absorptiometry measures of lean and fat mass at 9 to $10 \mathrm{y}$ of age. Am J Clin Nutr 84:739-747

53. Leary SD, Smith GD, Rogers IS, Reilly JJ, Wells JC, Ness AR 2006 Smoking during pregnancy and offspring fat and lean mass in childhood. Obesity (Silver Spring) $14: 2284-2293$

54. Williams JE, Wells JC, Wilson CM, Haroun D, Lucas A, Fetwrell MS 2006 Evaluation of lunar prodigy DEXA for assessing body composition in healthy persons and patients by comparison with the criterion 4-component model. Am J Clin Nutr 83:1047-1054

55. Wong WW, Hergenroeder AC, Stuff JE, Butte NF, Smith EO, Ellis KJ 2002 Evaluating body fat in girls and female adolescents: advantages and disadvantages of DEXA. Am J Clin Nutr 76:384-389

56. Gordon-Larsen P, Adair LS, Nelson M, Popkin BM 2004 Five-year obesity incidence in the transition period between adolescence and adulthood: the National Longitudinal Study of Adolescent Health. Am J Clin Nutr 89:569-575

57. Lin BH, Huang CL, French SA 2004 Factors associated with women's and children's body mass indices by income status. Int J Obes Relat Metab Disord 28:536542

58. Bogen DL, Hanusa BH, Whitaker RC 2004 The effect of breast-feeding with and without formula use on the risk of obesity at 4 years of age. Obes Res 12:1527-1535

59. Davey-Smith G, Ebrahim S 2005 What can Mendelian randomisation tell us about modifiable behavioural and environmental exposures. BMJ 330:1076-1079

60. Kirkwood BR, Sterne JA 2003 Essential Medical Statistics. Blackwell Publishing, New York, pp 77-96

61. Whitaker RC 2002 Understanding the complex journey to obesity in early adulthood. Arch Intern Med 136:923-925

62. Muthen B 2004 Latent variable analysis: growth mixture modelling and related techniques for longitudinal data. In: Kaplan D (ed) Handbook of Quantitative Methodology for the Social Sciences. Sage Publications, Newbury Park, CA, pp 345-368

63. Windle M, Grunbaum J, Elliott M, Tortolero SR, Berry S, Gililand J, Kanouse DE, Parcel GS, Wallander J, Kelder S, Collins J, Kolbe L, Schuster M 2004 Healthy passages: a multilevel, multimethod, longitudinal study of adolescent health. Am J Prev Med 27:164-172

64. Mustillo S, Worthman C, Erklani A, Keeler G, Angold A, Costello EJ 2003 Obesity and psychiatric disorder: developmental trajectories. Pediatrics 111:851-859 
65. Gortmaker SL, Peterson K, Wiecha J, Sobol AM, Dixit S, Fox MK, Laird N 1999 Reducing obesity via a school-based interdisciplinary intervention among youth: Planet Health. Arch Pediatr Adolesc Med 153:409-418

66. Robinson TN 1999 Reducing children's television viewing to prevent obesity: a randomized controlled trial. JAMA 282:1561-1567

67. Owen CG, Martin RM, Whincup PH, Davey-Smith G, Gillman MW, Cook DG 2005 The effect of breast-feeding on mean body mass index throughout life. Am J Clin Nutr 82:1298-1307

68. Harder T, Bergman R, Lallischrigg G, Plagerman A 2005 Duration of breast-feeding and risk of overweight: a meta-analysis. Am J Epidemiol 162:397-403

69. Arenz S, Ruckerl R, Koletzko B, Von Kries R 2004 Breast-feeding and childhood obesity - a systematic review. Int J Obes Relat Metab Disord 28:1247-1256

70. Sterne JA, Egger M, Davey-Smith G 2001 Systematic reviews in health care: investigating and dealing with publication and other biases in meta-analysis. BMJ 323:101-105

71. Baird J, Fisher D, Lucus P, Kleinjen J, Roberts H, Law C 2005 Being big or growing fast: systematic review of size and growth in infancy and later obesity. BMJ 331:929

72. Vanitallie TB 2006 Sleep and energy balance. Metabolism 55:S30-S35
73. Taheri S 2006 The link between short sleep duration and obesity. Arch Dis Child 91:881-884

74. Sahota P, Rudolf MC, Dixey R, Hill AJ, Barth JH, Cade J 2001 Randomised controlled trial of primary school based intervention to reduce risk factors for obesity. BMJ 323:1029-1032

75. Caballero B, Clay T, Davis SM, Ethelbah B, Rock BH, Lohman T, Norman J, Story M, Stone EJ, Stephenson L, Stevens J 2003 Pathways: a school-based, randomized controlled trial for the prevention of obesity in American Indian school children. Am J Clin Nutr 78:1030-1038

76. Reilly JJ, Kelly L, Montgomery C, Williamson A, Fisher A, McColl JH, Lo Conte R, Paton JY, Grant S 2006 Physical activity for obesity prevention in pre-schoo children: cluster randomised controlled trial. BMJ 333:1041

77. Robinson TN, Sirard JR 2005 Preventing childhood obesity: a solution oriented research paradigm. Am J Prev Med 2:104-201

78. Kramer MS, Guo T, Platt RW, Vanilovich I, Sevkovskaya Z, Dzikovich I, Michaelsen KF, Dewey K Promotion of Breastfeeding Intervention Trials Study Group 2004 Feeding effects on growth during infancy. J Pediatr 145:600605 